\title{
Turning the lens onto our own language: Engaging in critical reflexivity in the pursuit of social change
}

\author{
CHR IST I E M A L L I N O N ${ }^{\mathrm{a}}$ A N D \\ A N N H . CHARIT Y H U D E Y ${ }^{b}$ \\ ${ }^{a}$ University of Maryland, Baltimore County, USA \\ ${ }^{b}$ University of California, Santa Barbara, USA
}

"Yes, but how do you deal with resistant teachers?" Sociolinguists have asked us this question more times than we can count.

The question is a fair one. The concept of teacher resistance is now common lore among sociolinguists, who have heard about or who have experienced the rejection of well-intended efforts to bring linguistic knowledge to classrooms and schools. When we explain that we have had hardly any 'resistant' teachers - only two we can recall, over the course of working with thousands of teachers for the past decade - we are generally met with incredulity, quickly followed by a request to learn how we've made it work.

As Mark Lewis points out, a persistent assumption in our field is that if sociolinguists present our facts to individuals, it will change their minds - and thereby bring about social change. But this overreliance on the individual as the locus of social change, Lewis argues, is a major theoretical limitation because it diverts our attention away from considering broader systematic and structural barriers and solutions to social change.

Let's consider again the concept of the 'resistant' teacher. In an individual-centered model of social change, 'resistant' teachers who fail to adopt new knowledge are positioned as roadblocks, as people who are consciously or unconsciously impeding change. This framing borders on the teacher-blaming discourse that often circulates within the US. It also ignores the structural position of teachers, who often must abide by externally imposed rules and follow principles established by their own schools and school systems. Moreover (though Lewis does not overtly tackle this aspect), such framing unduly privileges sociolinguists as being the sole experts, ready to deliver facts to change the world if only others would receive them. By positioning ourselves as knowledge-bearers and others as holders of flawed or limited beliefs, our attention is diverted away from considering broader systems of power, in which not only others but also ourselves as scholars within disciplines are located.

As Lewis asserts, in order to move forward, we must unearth and interrogate these assumptions. Drawing upon scholarship from Jane Hill and others who tackle the question of language ideologies, Lewis explains, 'There is particular need to investigate how academic scholarship has produced and continues to 
produce knowledge about language in ways linked to existing systems of marginalization' (Lewis, this issue, p. 340). To that end, Lewis recommends that we engage in critical reflexivity, working to examine problematic disciplinary assumptions that undergird how we are trained to frame and address social problems. He gives a nod to frameworks that integrate critical reflexivity into the research design, such as those grounded in collaborative partnerships and/or that follow a culturally responsive approach, and emphasizes the particularly clear need to engage in 'teacher training efforts' along these lines.

But the article, which is primarily theoretical, stops short of including literature that delineates how sociolinguists can do the work of engaging in critical reflexivity or that describes what such interventions might look like-which is, we suspect, exactly what most sociolinguists who read this article are going to want to know... how specifically should we do things differently? What concrete actions should we take? How do we impact policy? To that end, in this commentary, we pick up where Lewis leaves off, focusing on the context of working with educators to provide some guidance for how sociolinguists can engage in critically reflexive ways about what we do.

Much in line with Lewis, we call on sociolinguists to interrogate how our own beliefs, ideologies, assumptions, and language can serve to marginalize the very groups that we aim to reach, in ways that can impede social change. First, we must reject our own marginalizing practices. It is nothing short of hypocritical to expect educators (and other groups) to do what we do not do ourselves. We ask educators in school settings to make space for their culturally and linguistically diverse students to speak - and write - in their own languages and language varieties. How many of us, in our own college and university classrooms, do the same? As sociolinguists, we espouse a value of multilingualism, and encourage educators to do so as well. How do we reconcile this with the fact that our own academic spaces - our classrooms, our academic writing, our conference papers, and the like - are largely monolingual? We take issue with the standardized tests used in K-12 settings in the USA and point out inherent linguistic biases, yet many of our graduate programs still rely on the antiquated model of standardized tests to gain admittance. We compel educators to support and build linguistic and cultural diversity in their classrooms, yet our own discipline is one of the least diverse in the academy (Friedman \& Reed 2014; Linguistic Society of America 2015). Any wellinformed K-12 teacher could look at our own practices, compare them to what we are telling her to do, and question it as a double standard.

Second, we must reject our own marginalizing language. If we value working with teachers and the public, we must respect them and their intellectual queries, which we signal (or fail to signal) through our own words. When we refer to teachers as 'resistant', we position them as failing to comprehend or follow our expert recommendations. When someone asks, "You're a linguist, so how many languages do you speak?", and we laugh or scoff, not only do we send a message that their question is uninformed, we also suggest that there is something nonlinguistic about 
speaking multiple languages. When a teacher asks about her students' use of texting, and we respond, "That's not really linguistics", we draw boundaries around our discipline and relegate her intellectual curiosity to an irrelevancy through the use of 'us versus them' language that, as we well know, makes ingroups feel included, while out-groups are excluded. When a high school student tries to tell us about their 'slang', and we correct them with what the 'real' terminology should be, we lay claim to their language rather than aiding them in their own linguistic discovery. When we use social media to proliferate memes that joke about the uninformed lay public, we are activating and spreading harmful ideologies about the esoteric nature of linguistics and the inaccessibility of academia. When we engage in 'mythbusting' - taking direct aim at other people's long-held assumptions and common beliefs in order to confront misperceptions - we risk the subtle reinforcement through repetition of the very myths that we want to obliterate, thereby spreading misinformation (Schwarz, Newman, \& Leach 2016). In addition, we risk causing defensiveness among audience members, who may stop listening. Once they stop listening, they also stop wanting to collaborate with us.

Nothing impedes social change more than alienating a key constituency. For teachers, one of the prime groups who sociolinguists want to reach, we must do better. As sociolinguists, we are not somehow exempt from the influence of language ideologies. Without interrogating our own social positions, practices, and assumptions, the biases that we hold and the biases that we express through our own language can affect our interactions with others in ways that can prevent us from carrying out ethically responsible research relationships (see also Zimman 2017). The study of language in society is not exclusively our intellectual domain; in other words, people actually do know some things about their own language, and the burden of communication is on us to learn what they know. In our own work, this collaborative model has been foundational and successful (see e.g. Mallinson, Charity Hudley, Strickling, \& Figa 2011). We have found that educators have immensely important insights about language and teaching, which are necessary to incorporate when working toward educational equity. In our partnerships, the learning goes both ways, challenging the very notion of a dichotomy between researcher and researched, between knowledge holder and knowledge receiver.

In this commentary, we have offered some specific recommendations for how sociolinguists can interrogate our own disciplinary-based ideologies and assumptions and thereby improve our own communication, as a critical component of our engagement work with educators and the public. Introspection can be a challenging and difficult task, but the move toward empowerment models of research and engagement requires making fundamental shifts in how we as sociolinguists think about, talk about, and talk with our community partners. The tool of critical reflexivity is not sufficient, but it is necessary, as we build a comprehensive decolonizing, social justice-oriented framework of language and social change. 


\title{
R E F E R E N C ES
}

Friedman, Lauren, \& Alyson Reed (2014). The state of linguistics in higher education: Annual report 2013. Washington, DC: Linguistic Society of America. Online: http://www.linguisticsociety.org/ files/Annual_Report_2013.pdf; accessed December 16, 2014.

Linguistic Society of America (2015). Annual report: The state of linguistics in higher Education. Online: http://www.linguisticsociety.org/resource/state-linguistics-higher-education-annual-report; accessed on April 13, 2016.

Mallinson, Christine; Anne H. Charity Hudley; Laura Rutter Strickling; \& Morgan Figa (2011). A conceptual framework for promoting linguistic and educational change. Language and Linguistics Compass 5(7):441-53.

Schwarz, Norbert; Eryn Newman; \& William Leach (2016). Making the truth stick \& the myths fade: Lessons from cognitive psychology. Behavioral Science \& Policy 2(1):105-14.

Zimman, Lal (2017). Working with transgender communities. In Christine Mallinson, Becky Childs, \& Gerard Van Herk (eds.), Data collection in sociolinguistics, 2nd edn., 49-52. New York: Routledge.

(Received 31 October 2017)

Address for correspondence:

Christine Mallinson

University of Maryland,

Baltimore County

1000 Hilltop Circle

Baltimore, MD 21250, USA

mallinson@umbc.edu

\section{Crafting a more integrated, specific, and community-sensitive approach to applied sociolinguistics}

\author{
J O H N R . R I C K F O R D \\ Stanford University, USA
}

A sociolinguist's first reaction to Lewis' critique of Labov's thirty-five-year-old principle of error correction (PEC) would likely be defensive or dismissive. While never formulated as the full-fledged 'theory of social change' Lewis portrays it to be, the PEC has indeed offered a valuable 'theoretical starting place for diverse social-change efforts' (Lewis, this issue, p. 326) by (socio)linguists over the years, repeatedly allowing us to use our technical training to provide more accurate diagnoses of language-related social issues than nonlinguists could, and thereby paving the way for their successful (re)solution. An early example is the 1985 trial of Paul 